\title{
ANALISIS PREDIKSI POTENSI KEBANGKRUTAN PT INDO ASIA SUKSES DENGAN MODEL ZMIJEWSKI DAN MODEL SPRINGATE
}

\author{
Willy \\ Program Studi Magister Manajemen Universitas Tarumanagara \\ willy.ww192@gmail.com
}

\begin{abstract}
This research aims to analyze potential bankruptcies of PT Indo Asia Sukses using Zmijewski and Springate method in period of 2016-2018. The data used is Primary data coming from the company. This research uses qualitative method with two data collections, those are documentation and theoritical study method. The result of research shows that: (1) According to Zmijewski X-Score, the company was in good condition with the negative result in 2016-2018. (2) According to Springate S-Score, the company was in good condition in 2016-2018, but the first quarter of 2017 showed the company had potential to get bankrupt. According to the result of research, it hoped that the company could improve the sales beacuse the research shows that low in sales could get the company bankrupt in first quarter of 2017 and the company could gain more awareness of financial if similar condition happening in the future.
\end{abstract}

Abstrak: Penelitian ini bertujuan untuk menganalisa potensi kebangkrutan PT Indo Asia Sukses dengan menggunakan Model Zmijewski dan Model Springate pada periode 20162018. Data yang digunakan adalah data primer. Penelitian ini menggunakan metode qualitatif dengan dua cara pengumpulan data, yaitu dokumentasi dan studi pustaka. Hasil penelitian menunjukkan bahwa: (1) Menurut Zmijewkski X-Score, perusahaan berada pada kondisi sehat dengan nilai negatif pada periode 2016-2018. (2) Menurut Springate S-Score, perusahaan berada kondisi yang sehat pada periode 2016-2018, kecuali periode kuartal pertama tahun 2017 yang menunjukkan bahwa perusahaan memiliki potensi kebangkrutan pada periode itu. Berdasarkan hasil penelitian, diharapkan dapat meningkatkan penjualan karena penelitian ini menunjukkan bahwa penjualan yang rendah dapat menimbulkan potensi kebangkrutan pada kuartal pertama tahun 2017 dan perusahaan bisa lebih memperhatikan kondisi keuangan apabila kondisi yang sama terjadi lagi.

Keywords: Zmijewski, Springate, Bankruptcy prediction, X-Score, S-Score.

\section{PENDAHULUAN}

PT Indo Asia Sukses merupakan perusahaan yang bergerak dalam bidang importir, supplier dan trading. Setiap perusahaan didirikan dengan harapan akan menghasilkan profit sehingga mampu untuk bertahan dan berkembang dalam jangka panjang yang tak terbatas. Hal ini berarti dapat diasumsikan bahwa perusahaan akan terus hidup dan diharapkan tidak akan mengalami likuidasi. Dalam praktik, asumsi seperti diatas tidak selalu menjadi kenyataan. Seringkali perusahaan yang telah beroperasi dalam jangka waktu tertentu terpaksa bubar karena mengalami fianncial distress yang berujung pada kebangkrutan (Wulandari, 2017).

Analisa Kebangkrutan dilakukan untuk memperoleh peringatan awal kebangkrutan tersebut berupa tanda-tanda kebangkrutan. Semakin awal ditemukannya indikasi kebangkrutan tersebut, semakin baik bagi pihak manajemen karena pihak manajeman bias melakukan perbaikan-perbaikan (Mamduh dan Halim, 2003). 


\section{LANDASAN TEORITIS}

\section{Kebangkrutan}

Menurut Ambarwati (2017) Kebangkrutan adalah kesulitan keuangan yang sangat parah sehingga perusahaan tidak mampu menjalankan operasi perusahaan dengan baik. Untuk mengetahui tanda-tanda awal kebangkrutan, salah satu cara yang dilakukan adalah menerapkan model prediksi kebangkrutan.

Wulandari (2017) menyatakan perusahaan dapat dikatakan bangkrut apabila perusahaan itu mengalami kesulitan yang ringan (seperti masalah likuiditas), dan sampai kesulitan yang lebih serius, yaitu solvable (utang lebih besar dibandingkan dengan asset).

\section{Model Kebangkrutan Zmijewski}

Zmijewski (1984) studi dalam prediksi kebangkrutan dilakukan oleh Zmijewski yang menambah validitas rasio keuangan sebagai alat deteksi kegagalan keuangan perusahaan Model yang berhasil dikembangkan yaitu sebagai berikut (Kleinert, 2014):

$\mathrm{X}=-4.3-4.5 \mathrm{X}_{1}+5.7 \mathrm{X}_{2}-0.004 \mathrm{X}_{3}$

Dimana:

$\mathrm{X} \quad$ = Indeks keseluruhan

$\mathrm{X}_{1}(\mathrm{ROA}) \quad=$ Laba bersih terhadap total aktiva

$\mathrm{X}_{2}$ (Debt Ratio) = Total kewajiban terhadap total asset

$\mathrm{X}_{3}$ (Current Ratio) $=$ Asset lancar terhadap kewajiban lancar

Model Zmijewski memiliki nilai cut off sebesar 0, artinya jika skor perusahaan kurang dari 0, maka perusahaan tersebut masuk dalam non financial distress. Sebaliknya, jika skornya lebih dari 0 , maka perusahaan diprediksi mengalami financial distress.

\section{Model Kebangkrutan Springate}

The Springate model dikembangkan oleh Gorgon L.V. Springate (1978) dengan menggunakan analisis multi diskriminan, untuk memilih empat dari 19 rasio keuangan yang popular sehingga dapat membedakan perusahaan yang beradap dalam zona bangkrut atau zona aman (Peter dan Yoseph, 2011). Model yang berhasil dikembangkan oleh Springate (Rajasekar et al, 2014) adalah sebgai berikut:

$\mathrm{S}=1.03 \mathrm{~A}+3.07 \mathrm{~B}+0.66 \mathrm{C}+0.4 \mathrm{D}$

Dimana:

$\mathrm{S} \quad=$ Indeks keseluruhan

A $\quad=$ Modal kerja terhadap total aktiva

B = Laba sebelum bunga dan pajak terhadap total aktiva

C = Laba sebelum pajak terhadap total kewajiban lancar

$\mathrm{D} \quad=$ Penjualan terhadap total aktiva

Springate mengemukakan nilai cut off yang berlaku untuk metode ini adalah 0,862 . Nilai skor yang lebih kecil dari 0,862 menunjukkan bahwa perusahaan tersebut diprediksi memiliki potensi terjadinya kebangkrutan. Tetapi jika nilai skor lebih besar dari 0,861 menunjukkan bahwa perusahaan tersebut diprediksi sehat. 


\section{METODE PENELITIAN}

\section{Objek dan Subjek Penelitian}

Subjek penelitian yang digunakan adalah PT Indo Asia Sukses. Dengan objek laporan keuangan PT Indo Asia Sukses perkuartal tahun 2016-2018.

\section{Sumber Data}

Data yang digunakan oleh penelitian ini adalah data primer, yaitu data laporan keuangan yang diperoleh dari internal subjek penelitian,. Berupa:

- Data laporan Neraca PT Indo Asia Sukses per kuartal tahun 2016-2018.

- Data laporan laba-rugi PT Indo Asia Sukses per kuartal tahun 2016-2018.

\section{Jenis Penelitian dan Metode Pengumpulan Data}

Jenis penelitian yang digunakan adalah penelitian kualitatif dengan menggunakan dua metode pengumpulan data:

- Metode Dokumentasi, berupa profil perusahaan dan laporan keuangan.

- Metode Studi Pustaka, berupa jurna-jurnal dan buku-buku mengenai teori analisa kebangkrutan perusahaan.

\section{HASIL DAN PEMBAHASAN}

\section{Model Kebangkrutan Zmijewski}

Hasil perhitungan variabel pembentuk dan nilai Zmijewski (X-Score) seperti dapat dilihat pada tabel dibawah ini:

\section{Tabel 1}

\begin{tabular}{|l|l|l|l|l|}
\hline Periode & $\mathrm{X}_{1}$ & $\mathrm{X}_{2}$ & $\mathrm{X}_{3}$ & $\mathrm{X}-$ Score \\
\hline $2016-\mathrm{Q} 4$ & 0.0440 & 0.0137 & 69.18 & -4.70 \\
\hline $2017-\mathrm{Q} 1$ & -0.0079 & 0.1070 & 7.39 & -3.68 \\
\hline $2017-\mathrm{Q} 2$ & -0.0045 & 0.1090 & 7.51 & -3.69 \\
\hline $2017-\mathrm{Q} 3$ & 0.2398 & 0.0740 & 11.88 & -5.00 \\
\hline $2017-\mathrm{Q} 4$ & 0.0276 & 0.0831 & 10.74 & -3.99 \\
\hline $2018-\mathrm{Q} 1$ & 0.1679 & 0.0530 & 17.29 & -4.82 \\
\hline $2018-\mathrm{Q} 2$ & 0.0560 & 0.0651 & 14.26 & -4.24 \\
\hline $2018-\mathrm{Q} 3$ & 0.1117 & 0.0882 & 10.72 & -4.34 \\
\hline
\end{tabular}

Berdasarkan tabel 4.1 hasil analisa perhitungan variabel Model Zmijewski dari periode kuartal keempat tahun 2016 hingga kuartal ketiga tahun 2018 membuktikan bahwa PT Indo Asia Sukses tidak memiliki potensi terjadinya kebangkrutan karena memiiki hasil yang negatif. Namum jika dilihat per rasio yang diteliti khususnya Return On Asset (X1), PT Indo Asia Sukses memiliki yang cukup banyak khususnya pada cash dan inventory. Namun masih tidak efektif dan efisien dalam pemanfaatan asset yang dimiliki dalam mencapai keuntungan maksimal.

Melalui indikasi ini, pemanfaatan asset yang effektif dan efisien harus dilakukan untuk mempertahankan perusahaan.

\section{Model Kebangkrutan Springate}

Hasil perhitungan variabel pembentuk dan nilai Zmijewski (X-Score) seperti dapat dilihat pada tabel dibawah ini: 
Tabel 2

\begin{tabular}{|l|l|l|l|l|l|}
\hline Periode & $\mathrm{A}$ & $\mathrm{B}$ & $\mathrm{C}$ & $\mathrm{D}$ & $\mathrm{S}$-Score \\
\hline 2016-Q4 & 0.9316 & 0.0440 & 3.2206 & 0.3121 & 3.35 \\
\hline 2017-Q1 & 0.6832 & -0.0079 & -0.0740 & 0.1838 & 0.70 \\
\hline 2017-Q2 & 0.7095 & -0.0045 & -0.0409 & 0.5516 & 0.91 \\
\hline 2017-Q3 & 0.8091 & 0.2398 & 3.2413 & 0.5174 & 3.91 \\
\hline 2017-Q4 & 0.8095 & 0.0276 & 0.3318 & 0.3395 & 1.27 \\
\hline 2018-Q1 & 0.8626 & 0.1679 & 3.1711 & 0.4458 & 3.68 \\
\hline 2018-Q2 & 0.8629 & 0.0560 & 0.8603 & 0.3804 & 1.78 \\
\hline 2018-Q3 & 0.8568 & 0.1117 & 1.2673 & 0.5017 & 2.26 \\
\hline
\end{tabular}

Berdasarkan tabel 4.2 hasil analisa perhitungan variabel Model Springate dari periode kuartal keempat tahun 2016 hingga kuartal ketiga tahun 2018 membuktikan bahwa PT Indo Asia Sukses memiliki potensi bangkrut khusus hanya pada pada kuartal pertama tahun 2017 yang memiliki S-Score < 0.862 yaitu 0.70 .

Melalui indikasi ini, tingkat penjualan tinggi menjadi salah satu hal terpenting agar perusahaan tetap bertahan dan menghindar dari potensi terjadinya kebangkrutan.

\section{Perbandingan Model Zmijewski dan Model Springate}

Tabel 3

\begin{tabular}{|l|l|l|l|l|}
\hline Periode & Zmijewski & Prediksi & Springate & Prediksi \\
\hline 2016-Q4 & -4.70 & Sehat & 3.35 & Sehat \\
\hline 2017-Q1 & -3.68 & Sehat & 0.70 & Bangkrut \\
\hline 2017-Q2 & -3.69 & Sehat & 0.91 & Sehat \\
\hline 2017-Q3 & -5.00 & Sehat & 3.91 & Sehat \\
\hline 2017-Q4 & -3.99 & Sehat & 1.27 & Sehat \\
\hline 2018-Q1 & -4.82 & Sehat & 3.68 & Sehat \\
\hline 2018-Q2 & -4.24 & Sehat & 1.78 & Sehat \\
\hline 2018-Q3 & -4.34 & Sehat & 2.26 & Sehat \\
\hline
\end{tabular}

Pada tahun 2017 kuartal pertama PT Indo Asia Sukses mengalami kondisi perusahaan yang bangkrut menurut Springate dengan nilai $0.70(<0.862)$ dan apabila kondisi pada periode tersebut dilihat melalui Model Zmijewski dimana tidak bangkrut tetapi memiliki score paling rendah dibandingkan periode lainnya. Hal ini terjadi karena nilai variabel A, B dan D lebih kecil, bahkan paling kecil dibandingkan dengan variabel A, B dan D pada periode lain. Hal ini terbukti dari working capital yang tinggi, asset yang melimpah dan penjualan yang rendah, yang menandakan PT Indo Asia Sukses pada saat itu tidak efektif dan efisien dalam pemanfaatan asset yang ada untuk mencapai keuntungan maksimal. Artinya apabila kondisi periode kuartal pertama tahun 2017 ini tetap berlanjut, maka perusahaan dengan asset yang banyak pun akan mengalami kebangkrutan karena tidak produktif.

\section{PENUTUP}

\section{Kesimpulan}

Berdasarkan pembahasan analisis yang telah dilakukan bab sebelumnya maka dapat diambil kesimpulan sebagai berikut:

- Hasil prediksi kebangkrutan menurut Menurut Zmijewski periode kuartal keempat tahun 2016 hingga periode kuartal ketiga tahun 2018 menyatakan bahwa PT Indo Asia Sukses tidak berpotensi terjadinya kebangkrutan dan mengalami kondisi perusahaan yang sehat dengan hasil nilai negatif dan sudah memenuhi kriteria perusahaan yang sehat.

- Hasil prediksi kebangkrutan menrurut Mode Springate periode kuartal keempat tahun 2016 hingga kuartal ketiga tahun 2018 menyatakan bahwa PT Indo Asia Sukses 
mengalamai kondisi bangkrut pada kuartal pertama tahun 2017 dengan nilai dibawah 0.862 yaitu 0.70

- PT Indo Asia Sukses memiiki potensi kebangkrutan pada periode kuartal pertama tahun 2017 menurut model Springate.

\section{Saran}

Berdasarkan penelitian yang telah dilakukan, maka ada beberapa saran yang diajukan:

- Perusahaan dapat mempertahankan kondisi keuangan yang sehat dengan meningkatkan penjulaan, sehingga pemanfaatan asset dapat lebih efektif dan efisien.

- Periode kuartal pertama tahun 2017 yang dinilai memiliki potensi bangkrut dapat menjadi poin bagi perusahaan untuk lebih memperhatikan kesehatan keuangan apabila kondisi yang sama terjadi lagi yaitu kondisi penjualan sedang menurun.

\section{DAFTAR PUSTAKA}

Ambarwati, Umi., Sudarwati dan Rochmi Widayanti. (2017). Financial Distress Dengan Metode Springate, Zmijewski, Fulmer, dan Altman Z-Score pada PT Tunas Baru lampung TBK di BEI. Jurnal Ekonomi, Universitas Islam Batik Surakarta, 1.

Elmabrok, Ali Abusalah., Mohammed and Ng Kim-Soon. (2012). Using Altman's Model and Current Ratio to Assess the Financial Status of Companies Quoted In the Malaysian Stock Exchange. International Journal of Scientific and Research Publications. Faculty of Technology Management, Business and Entrepreneurship, University Tun Hussein Onn Malaysia.

Hafiz Fauzan dan Fidya Sutiono. (2017). Perbandingan Model Altman Z-Score, Zmijewksi, Springate, dan Grover Dalam Memprediksi Kebangkrutan Perusahaan perbankan. Jurnal Akuntansi, Akademi Akuntansi Bina Insani, 2(1), 49-60.

Lagkas, T.D. and Papadopoulos, D. (2014). Financial Analysis Considering Distress Prediction Models of Telecommunications Companies Listed in Athens Stock Exchange International Journal of Decision Sciences, Risk and Management, 5(4), 376.

Mamduh dan Abdul Halim. (2003). Analisis Laporan Keuangan. Edisi Revisi. Yogyakarta: UPP AMP YKPN.

Peter dan Yoseph. (2011). Analisis Kebangkrutan Dengan Metode Z-Score Altman, Springate dan Zmijewski Pada PT. Indofood Sukses Makmur Tbk Periode 20052009. Jurusan Manajemen, Universitas Kristen Maranatha. Akurat Jurnal Ilmiah Akuntansi, 4.

Prihatini, Ni Made Evi Dwi dan Maria M. Ratna Sari. (2013). Analisis Prediksi Kebangkrutan dengan Model Grover, Altman Z-score, Springate dan Zmijewski pada perusahaan Food and Beverages di BEI. jurnal Akuntansi, Universitas Udayana, 5(3), 544-560.

Purnajaya., Komang Devi Methili, dan Ni K. Lely A. Merkusiwati. (2014). Analisis Komparasi Potensi Kebangkrutan dengan Metode Z-Score Altman, Springate, dan Zmijewski pada Industri Kosmetik yang Terdaftar di Bursa Efek Indonesia. Jurnal Akuntansi, Universitas Udayana, 7(1), 48-63. 
Rajasekar, Ashraf, Deo. (2014). An Empirical Enquiry on the Financial Distress of Navratna Companies in India. Journal of Accounting and Finance, 14 (3), 3-7.

Rismawaty. (2012). Analisis Perbandingan Model Prediksi Financial Distress Altman, Springate, Ohlson, Dan Zmijeski (Studi Empiris Pada Perusahaan Manufaktur Yang Terdaftar Di Bursa Efek Indonesia). Fakultas Ekonomi, Universitas Hasanudin Makasar.

Springate Gordon, L.V. (1978). Predicting the Possibility of Failure in a Canadian Firm/Gordon LV Springate. Simon Fraser University, 164.

Sugiyono. 2010. Metode Penelitian Bisnis. CV Alfabeta : Bandung

Suryani., Anti, Suhadak, dan Raden Rustam Hidayat. (2014). Pengaruh Rasio Capital Adequacy Ratio, Biaya Operasional per Pendapatan Operasional, Loan To Deposit Ratio, Net Interest Margin dan Non Performing Loan Terhadap Return On Assets. Jurnal Ekonomi, Universitas Brawijaya, 33(1), 2-6.

Wulandari, Emrinaldi Nur DP, dan Juita. (2017). Analisis Perbandingan Model Altman, Springate, Ohlson, Fulmer, CA-Score dan Zmijewski Dalam Memprediksi Financial Distress. Jurnal Ekonomi, Universitas Riau, 1(2), 2-18.

Zmijewski, M.E. (1984). Methodological Issues Related to the Estimation of Financial Distress Prediction Models. Journal of Accounting Research, $\quad$ 22, 59-82. 
